\title{
Implanty ślimakowe - wczoraj i dziś
}

\section{Cochlear implants - yesterday and today}

\section{Anna Piotrowska, Artur Lorens, Anita Obrycka, Henryk Skarżyński}

Instytut Fizjologii i Patologii Słuchu, Światowe Centrum Słuchu, Warszawa/Kajetany

Adres autora: Anna Piotrowska, Światowe Centrum Słuchu, Zakład Epidemiologii i Badań Przesiewowych, ul. Mokra 17, Kajetany, 05-830 Nadarzyn, e-mail: a.piotrowska@ifps.org.pl

\section{Streszczenie}

W pracy przedstawiono historię implantów ślimakowych, począwszy od pierwszych prób zastosowania stymulacji elektrycznej po czasy współczesne.

Słowa kluczowe: implanty ślimakowe • stymulacja elektryczna • częściowa głuchota • niedosłuch

\begin{abstract}
In the paper authors present the history of cochlear implants from the first trials with electric stimulation up to the present-day technology and qualification criteria.
\end{abstract}

Key words: cochlear implants • electric stimulation • partial deafness • hearing loss

System implantu ślimakowego jest elektroniczną protezą słuchu, która dzięki bezpośredniej stymulacji elektrycznej zakończeń nerwu słuchowego zastępuje uszkodzony narząd receptorowy ślimaka, gdyż powoduje wzbudzenie potencjałów czynnościowych w nerwie. System implantu ślimakowego złożony jest z części wewnętrznej, składającej się z odbiornika i stymulatora elektrycznego umieszczonych we wspólnej obudowie oraz wiązki elektrod, i części zewnętrznej - cyfrowego procesora mowy.

Część wewnętrzna jest wszczepiana operacyjnie. Kapsuła implantu umieszczana jest w niszy wytworzonej w kości skroniowej i przykryta płatem skórnym, natomiast wiązka elektrod jest wprowadzana do ślimaka. Część zewnętrzna implantu - procesor mowy przetwarza dźwięk na bodziec elektryczny zgodnie z określonym algorytmem, zwanym strategią kodowania mowy. Przetworzony sygnał przesyłany jest za pośrednictwem fal radiowych przez skórę do implantu. Znajdujące się w implancie źródła prądowe zapewniają odpowiednią stymulację nerwu słuchowego [1].

Historia implantów ślimakowych rozpoczęła się w 1790 r., kiedy to AlessandroVolta przeprowadził pierwszy eksperyment elektrostymulacji drogi słuchowej. Połączył ze stosem baterii przewodzące pręciki i umieścił je we własnych uszach. Powstałe doznanie opisał jako huk w głowie, po którym wystąpił dźwięk podobny do gotującej się, gęstej zupy.

Pierwszą operację wszczepienia urządzenia służącego do bezpośredniej elektrycznej stymulacji nerwu słuchowego przeprowadzili A. Djourno i Ch. Eyriès w 1957 r. w Paryżu. Urządzenie to nie pozwalało na rozumienie mowy, dawało jedynie poczucie dźwięków otoczenia, a po kilku miesiącach uległo uszkodzeniu. Zainspirowany dokonaniem Francuzów W. House rozpoczął badania na Uniwersytecie w Los Angeles. W 1961 r. kierowana przez niego grupa wszczepiła dwóm pacjentom elektrody, umożliwiając stymulację nerwu słuchowego. W 1964 r. J. Doyle, współpracujący wcześniej z W. Housem, po raz pierwszy wprowadził elektrodę do wnętrza ślimaka.

Pierwszy na świecie program leczenia głuchoty za pomocą implantów ślimakowych rozpoczął w 1972 r. w Stanach Zjednoczonych W. House [2]. Wykorzystywał on pierwszy produkowany seryjnie jednokanałowy system 3M. System ten uzyskał w roku 1984 dopuszczenie do stosowania klinicznego (FDA approval) u dorosłych, a w roku 1986 u dzieci powyżej 2 rż. Implanty te niestety okazały się bardzo awaryjne i zostały wkrótce wycofane $\mathrm{z}$ użytku klinicznego. Podobny program w Europie rozpoczą w 1973 r. C. H. Chouard [3] w Paryżu, a K. Burian w 1975 r. w Wiedniu [4].

Ze względu na ograniczenia technologiczne związane z poziomem rozwoju elektroniki w latach 70 . XX w. we wszystkich przypadkach stosowano systemy jednokanałowe, umożliwiające stymulację elektryczną za pośrednictwem jednej elektrody. Wyniki badań przeprowadzonych na modelu zwierzęcym wykazały jednak, że za pomocą implantu jednokanałowego nie jest możliwa dyskryminacja częstotliwości powyżej $2000 \mathrm{~Hz}$, co jest bardzo ważne 
dla rozumienia mowy. To skłoniło do podjęcia prac nad stworzeniem implantu wielokanałowego, które zapoczątkował w 1967 r. G. Clark w Australii [5]. Pierwsze systemy wielokanałowe wprowadzono w 1984 r. G. Clark w Melbourne i E. Lehnhardt w Hanowerze jako pierwsi rozpoczęli stosowanie implantów wielokanałowych w praktyce klinicznej [6,7]. W grudniu 1984 r. systemy implantów ślimakowych uzyskały po raz pierwszy dopuszczenie do szerokiego zastosowania klinicznego. Fakt ten zakończył etap eksperymentu ze stymulacją elektryczną, a rozpoczął nową erę terapii głuchoty i głębokiego niedosłuchu. Ważnym wydarzeniem lat 80 . było zatem uznanie implantów ślimakowych jako metody postępowania terapeutycznego i dopuszczenie tych urządzeń do stosowania klinicznego.

Lata 90. to intensywny rozwój technologii elektronicznej możliwej do stosowania w systemach implantów (powstanie cyfrowych układów scalonych wielkiej skali integracji) $\mathrm{z}$ jednej strony, a z drugiej znaczny postęp w pracach nad algorytmami przetwarzania dźwięku na bodziec elektryczny. B. Wilson w Research Triangle Institute w Północnej Karolinie opracował strategię CIS (ang. Continous Interleaved Sampling), a H. McDermott na Uniwersytecie w Melbourne opracował strategię SPEAK (ang. Spectral PEAK extraction) [8-10]. Zaowocowało to rozpowszechnieniem komercyjnych systemów implantów ślimakowych do zastosowań klinicznych, które pozwalały użytkownikom na osiąganie coraz lepszych wyników rozumienia mowy [8].

Program leczenia całkowitej głuchoty i głębokich niedosłuchów z wykorzystaniem implantów ślimakowych został zapoczątkowany w Polsce przez H. Skarżyńskiego w roku $1992[11,12]$.

Zgodnie z początkowymi wskazaniami klinicznymi wszczepienie implantu ślimakowego rozważano jedynie w przypadku całkowitej głuchoty u osoby dorosłej, a uzyskanie jakichkolwiek reakcji akustycznych w wyniku stymulacji elektrycznej uznawano za sukces [4]. Pierwszych kilkuset dorosłych pacjentów korzystało $\mathrm{z}$ implantu jednokanałowego, który umożliwiał jedynie odbiór podstawowych wrażeń dźwiękowych. W jednym na dwadzieścia przypadków dawał możliwość, w ograniczonym stopniu, rozumienia mowy [2]. Wraz z wprowadzaniem nowych rozwiązań technologicznych, w postaci systemów wielokanałowych, populacja użytkowników implantu ślimakowego na świecie znacząco i systematycznie wzrastała [13]. Wyniki osiągane przez pacjentów z implantami były coraz lepsze, a liczne publikacje i doniesienia potwierdzały rozumienie mowy w zestawach otwartych $[11,14,15]$. Na tej podstawie zaproponowano wszczepianie implantów dzieciom oraz pacjentom, którzy pomimo możliwości percepcji dźwięku w aparatach słuchowych nie uzyskiwali satysfakcjonującego poziomu rozumienia mowy [15]. Pierwsze dziecko, któremu w roku 1980 wszczepiono implant ślimakowy, miało 9 lat [16].

Zastosowanie implantów u pacjentów z takim niedosłuchem, który pozwalał jedynie na bardzo ograniczone rozumienie mowy w aparatach słuchowych, było kolejnym krokiem w kierunku rozszerzenia kryteriów kwalifikacji $[5,15]$. Po wszczepieniu implantu ślimakowego pacjenci ci uzyskują obecnie możliwość komunikacji na drodze słuchowej, bez konieczności odczytywania mowy z ust [17-19].
Tak więc audiologiczne kryteria kwalifikacji ewaluowały od obustronnej głuchoty ( $>110 \mathrm{~dB} \mathrm{HL}$ ) na początku lat 80., poprzez znaczny niedosłuch (>70 dB HL) w latach 90. $[10,20]$, do aktualnego kryterium opartego na wynikach badań nadprogowych z wykorzystaniem testów słownych, tj. rozumienia zdań w zestawie otwartym na poziomie poniżej 50\% w optymalnych warunkach odsłuchowych lub dyskryminacji słów jednosylabowych nie większej niż 40\% [21]. Z tego faktu wynika, iż obecnie wielu pacjentów kwalifikowanych do wszczepienia implantu ślimakowego posiada tzw. ograniczoną czułość słuchu, co umożliwia im ograniczone rozumienie mowy w aparatach słuchowych [22].

Rozwój programów implantów ślimakowych pozwolił również na potwierdzenie skuteczności stosowania implantów u dzieci, dowodząc, że im wcześniej zastosujemy stymulację elektryczną u dziecka z głuchotą wrodzoną, tym większe są jego szanse na rozwój słuchowy na poziomie zbliżonym do rozwoju dziecka słyszącego [23-25]. W roku 1990 Federal Drug Administration (FDA) zatwierdziło stosowanie implantu Nucleus 22 u dzieci poniżej 2 rż. Zgodnie $\mathrm{z}$ aktualnymi wytycznymi FDA wszczepienie implantu ślimakowego jest dopuszczalne u dzieci w wieku 12 miesięcy. Wybrane ośrodki otochirurgiczne na świecie proponują obniżenie tego wieku poniżej $1 \mathrm{rż}$. [26,27].

W świetle obecnej wiedzy dużego znaczenia nabiera zachowanie po wszczepieniu implantu czułości słuchu w stanie zbliżonym do przedoperacyjnego, gdyż stwarza to możliwość zastosowania jednoczasowej stymulacji elektryczno-akustycznej. W roku 1999 von Ilberg (Niemcy) wykazał, że jednoczesne zastosowanie implantu ślimakowego i aparatu słuchowego w tym samym uchu może dać lepsze efekty w rozumieniu mowy niż zastosowanie samego implantu lub samego aparatu [28]. Metoda, w której jednocześnie stosuje się w tym samym uchu implant ślimakowy i aparat słuchowy, została nazwana stymulacją elektryczno-akustyczną. Łączona stymulacja może poprawić jakość słyszenia oraz zwiększyć stopień rozumienia mowy w porównaniu z wynikami osiąganymi z zastosowaniem tylko stymulacji akustycznej (aparatu słuchowego) lub tylko stymulacji elektrycznej (implantu) [22,29,30].

Niezwykle nowatorskim rozwiązaniem terapeutycznym była nowa metoda leczenia częściowej głuchoty (ang. Partial Deafness Treatment, PDT) zaproponowana przez Skarżyńskiego [30]. Metoda ta przeznaczona jest dla osób, których ubytek słuchu charakteryzuje się prawidłową lub zbliżoną do prawidłowej czułością słuchu dla niskich częstotliwości, przy całkowitej głuchocie dla średnich i wysokich częstotliwości. Taki rodzaj ubytku słuchu został określony mianem „częściowej głuchoty” (rycina 1).

U pacjentów tych próby protezowania za pomocą aparatów słuchowych nie dają satysfakcjonującego efektu. Brak czułości słuchu dla wysokich częstotliwości nie pozwala na wystarczającą kompensację ubytku słuchu na drodze akustycznego wzmocnienia dźwięku realizowanego przez aparat słuchowy. Pacjenci z częściową głuchotą nie byli dotychczas kwalifikowani do wszczepienia implantu ślimakowego, ponieważ istniała obawa, że podczas operacji zniszczony zostanie sprawnie funkcjonujący fragment ślimaka. Pierwszą w Polsce, a zarazem na świecie, operację wszczepienia implantu ślimakowego 

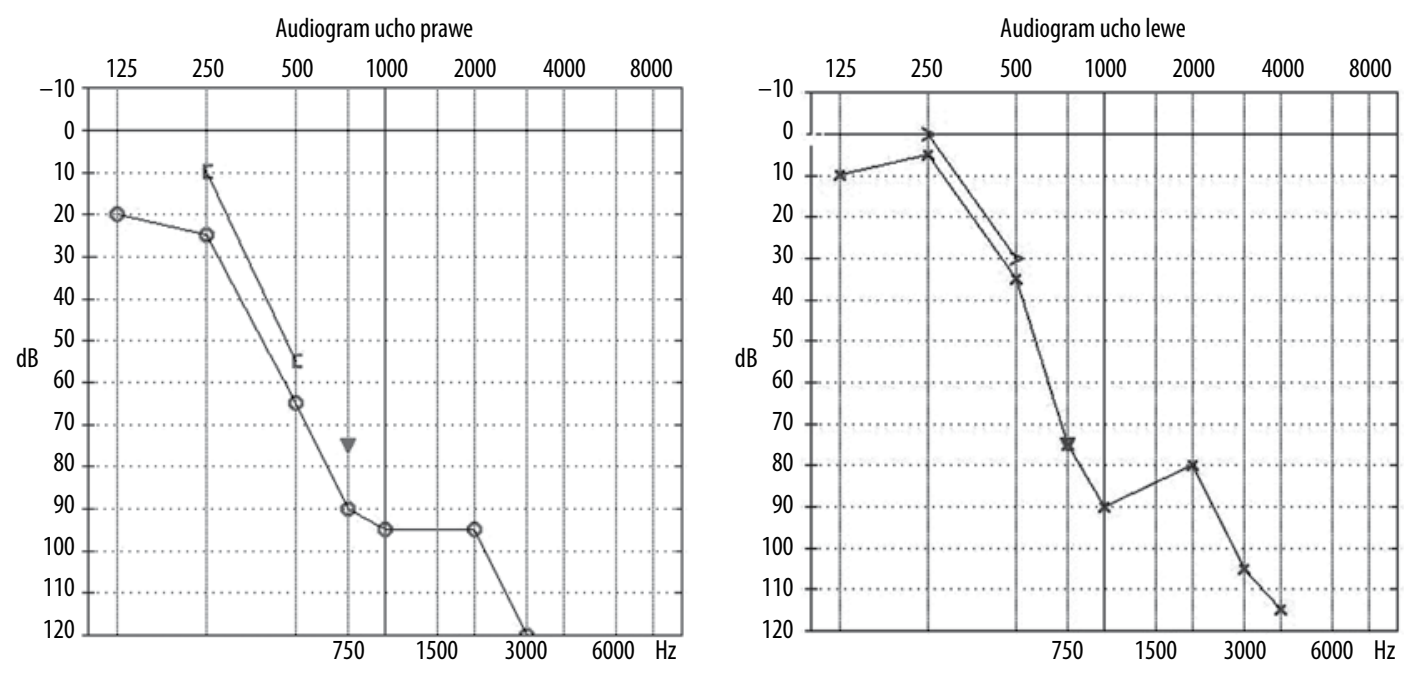

Rycina 1. Przykładowy audiogram pacjenta z częściową głuchotą w uchu prawym i lewym

Figure 1. Example of a partial deafness audiogram

$\mathrm{u}$ dorosłego pacjenta $\mathrm{z}$ częściową głuchotą przeprowadził H. Skarżyński 12 lipca 2002 r. w Instytucie Fizjologii i Patologii Słuchu (IFPS) w Warszawie [30]. Pierwszą w świecie tego typu operację u dziecka z częściową głuchotą wykonał H. Skarżyński 27 września 2004 roku [29]. Badania prowadzone w ostatnich latach w IFPS wykazały, że zastosowanie stymulacji elektryczno-akustycznej za pośrednictwem implantu ślimakowego, przywracającej słyszenie wysokich i średnich częstotliwości, przy jednoczesnym zachowaniu czułości słuchu pacjenta dla niskich częstotliwości stanowi skuteczną metodę terapii dla znacznej grupy pacjentów. W roku 2009 H. Skarżyński zaproponował nową koncepcję leczenia częściowej głuchoty (PDT) oraz klasyfikację uszkodzeń słuchu i leczenia niedosłuchów różnego typu przy wykorzystaniu stymulacji elektrycznej i akustycznej [31].

Jednym z kluczowych warunków, który musi być spełniony, aby możliwe było kliniczne zastosowanie proponowanych metod, jest takie wprowadzenie elektrody implantu do ucha wewnętrznego, aby możliwe było zachowanie czułości słuchu w zakresie niskich częstotliwości w stanie zbliżonym do tego sprzed operacji. W tym celu H. Skarżyński opracował atraumatyczną technikę chirurgiczną z zastosowaniem dojścia do ucha wewnętrznego przez okienko okrągłe [22,29-31]. Jako że w ostatnich latach problem zachowania czułości słuchu nabiera istotnego znaczenia w chirurgii implantów ślimakowych, opracowuje się nowe rodzaje elektrod w celu zminimalizowania rozległości uszkodzeń [32,33].

W tym samym roku, w którym wykonano pierwszą udaną operację wszczepienia implantu ślimakowego u pacjenta z częściową głuchotą (2002), firma Cochlear wprowadziła na rynek, w celu zmniejszenia inwazyjności związanej $\mathrm{z}$ umieszczaniem elektrody implantu $\mathrm{w}$ uchu wewnętrznym, zmodyfikowaną elektrodę okołowrzecionkową z odpowiednio ukształtowaną końcówką tzw. Softip ${ }^{\circledR}$ - Nucleus 24 Contour Advance [34,35]. Natomiast firma Advanced Bionics opracowała nową strategię kodowania dźwięku - HiResolution, ze znacząco zwiększoną prędkością stymulacji pozwalającą na wzrost rozdzielczości czasowej odbieranego sygnału [36]. W roku 2003 firma ta opracowała nowy implant HiRes $90 \mathrm{~K}$ oraz nowy procesor $\mathrm{Au}-$ ria, które umożliwiały wykorzystanie nowej technologii.

Od roku 2006 firma Med-El wprowadzała nowe atraumatyczne elektrody $z$ rodziny Flex [37-39]. Na 9 Europejskiej Konferencji Implantów Ślimakowych u Dzieci (ESPCI 2009) T. Lenarz przedstawił wyniki stosowania nowych elektrod firmy Cochlear: Hybrid-L oraz Hybdrid-S. H. Skarżyński zaprezentował wyniki kliniczne nowej eksperymentalnej elektrody SRA (ang. Straight Research Array), która została zaprojektowana we współpracy z firmą Cochlear, specjalnie dla zachowania resztek słuchowych, a zastosowana $\mathrm{w}$ procedurze dojścia do ślimaka przez okienko okragłe. Nowy implant, pod nazwą CI422, został dopuszczony do stosowania klinicznego w roku 2011 [40].

Dla potrzeb pacjentów z częściową głuchotą projektowano również nowe procesory mowy, umożliwiające jednoczasową stymulację akustyczną i elektryczną (EAS). W roku 2005 firma Med-El wprowadziła pierwszy system EAS z procesorem DUET [41]. Podobny system firmy Cochlear z procesorem Hybrid został wprowadzony w roku 2008.

Równolegle do postępu w obszarze leczenia częściowej głuchoty udoskonalano systemy implantu ślimakowego przeznaczone dla pacjentów z głębokim niedosłuchem. W roku 2005 firma Cochlear zaprezentowała procesor Nucleus Freedom z ochroną przed penetracją czynników zewnętrznych IP44 oraz nowym algorytmem przetwarzania sygnału, pozwalającym na dopasowanie parametrów pracy urządzenia do zmiennej sytuacji akustycznej w otoczeniu pacjenta.

W roku 2006 firma Med-El opracowała nową strategię przetwarzania sygnału w procesorach mowy, zapewniającą możliwość odbioru struktury czasowej sygnału - technologię Fine Hearing. W tym samy roku firma Advanced Bionics wprowadziła technologię tzw. kanałów wirtualnych - HiRes Fidelity 120, zwiększających liczbę kanałów przekazywania informacji do drogi słuchowej $[42,43]$. 
W roku 2009 firma Cochlear wprowadziła kolejny procesor mowy - Nucleus $5 \mathrm{z}$ wyższym stopniem ochrony przed penetracją czynników zewnętrznych (IP57) oraz nowymi algorytmami przetwarzania sygnału, pozwalającymi na zmianę parametrów pracy urządzenia w zależności od sytuacji akustycznej w otoczeniu. System Cochlear Nucleus 6 - wyposażony w procesor dźwięku, który automatycznie rozpoznaje „otoczenie akustyczne” - pojawia się na rynku na początku 2014 roku. W roku 2010 nową strategię przetwarzania sygnału - ClearVoice wprowadza do swoich systemów firma Advanced Bionics. Technologia ta umożliwia analizę w czasie rzeczywistym otoczenia akustycznego pacjenta i dopasowanie pracy urządzenia do zmiennych warunków [44-46]. Nowy procesor tej firmy - Neptune pojawia się na rynku w roku 2012. Cechą szczególną tego procesora jest pełna wodoszczelność, co czyni go dobrym rozwiązaniem dla pacjentów czynnie uprawiających sporty wodne lub których praca wymaga przebywania w warunkach zwiększonej wilgotności powietrza. Pierwszym jednomodułowym procesorem jest urządzenie RONDO firmy Med-El dostępne od 2013 roku.

W roku 2013 grupa robocza HEARRING, utworzona $\mathrm{z}$ inicjatywy H. Skarżyńskiego przez przedstawicieli wiodących światowych ośrodków otochirurgicznych [47], opracowała nową Klasyfikację Zachowania Słuchu po Wszczepieniu Implantu Ślimakowego. Innowacyjnością tej Klasyfikacji jest zastąpienie dotychczasowej metodologii oceny stopnia zachowania słuchu, wykorzystującej wartości bezwzględnej zmiany progów słyszenia, na rzecz obliczania zmiany wartości progów słyszenia jako wielkości względnej, co pozwala na skuteczne stosowanie tej Klasyfikacji niezależnie od przedoperacyjnych wartości progu słyszenia w uchu implantowanym.

W ciągu ostatnich lat zgromadzono wystarczające dowody na to, że wszczepienie implantu ślimakowego zapewnia lepsze korzyści słuchowe wówczas, gdy struktury ucha wewnętrznego są zachowane, niezależnie od rodzaju i stopnia niedosłuchu. Zatem zachowanie struktur ucha wewnętrznego powinno być obecnie celem u każdego pacjenta. Dlatego też jednym z przyszłych rozwiązań technologicznych w dziedzinie implantów ślimakowych jest projekt tzw. spersonalizowanej elektrody, która łączy funkcje diagnostyczne i terapeutyczne w zależności od indywidualnych cech pacjenta.

Producenci implantów ślimakowych prowadzą również prace nad stworzeniem systemu całkowicie wszczepialnego, tj. takiego, który nie będzie wymagał korzystania z części zewnętrznej.

W ciągu ostatnich lat wiele uwagi poświęca się ponadto zagadnieniom związanym $\mathrm{z}$ obustronnym wszczepieniem implantu ślimakowego pacjentom $\mathrm{z}$ różnych grup wiekowych. National Institute for Health and Care Excellence (NICE) zaleca jednoczasowe wszczepianie dwóch implantów ślimakowych jako postępowanie $\mathrm{z}$ wyboru zarówno u dzieci, jak i u osób dorosłych, u których zdiagnozowano znaczny lub głęboki niedosłuch odbiorczy. Stosunkowo nowym wskazaniem do stosowania implantu ślimakowego są szumy uszne występujące u pacjentów $\mathrm{z}$ niedosłuchem jednostronnym. Zastosowanie stymulacji elektrycznej w tej grupie może znacząco zredukować intensywność i dokuczliwość szu$\mathrm{mu}$, jak również poprawić słyszenie kierunkowe [48-50].

Potwierdzone licznymi badaniami możliwości skutecznego leczenia $\mathrm{z}$ wykorzystaniem systemu implantu ślimakowego różnych grup pacjentów dokumentują przełom, jaki dokonał się w terapii osób niesłyszących i niedosłyszących. Dzięki pojawieniu się nowych technologii oraz metod diagnostycznych i chirurgicznych zniesiono w znacznym stopniu ograniczenia i bariery wynikające $z$ niepełnosprawności słuchowej. Wszczepienie implantu ślimakowego jest obecnie powszechnie stosowaną formą rehabilitacji medycznej osób z niedosłuchem.

Projekt został sfinansowany ze środków Narodowego Centrum Nauki przyznanych na podstawie decyzji nr DEC-2013/09/B/ ST7/04213.

\section{Piśmiennictwo:}

1. Śliwińska-Kowalska M. Audiologia kliniczna. Mediton; 2005.

2. House WF, Urban J. Long term results of electrode implantation and electronic stimulation of the cochlea in man. Ann Otol Rhinol Laryngol, 1973; 82: 504-17.

3. Chouard CH, MacLeod P. Implantation of multiple intracochlear electrodes for rehabilitation of total deafness: preliminary report. Laryngoscope, 1976; 86: 1743-51.

4. Burian K, Hochamir-Desoyer IJ, Eisenwort B. The Vienna cochlear implant program. Otolaryngologic Clinics of North America, 1986; 19: 313-28.

5. Zeng FG, Popper AN, Fay RR. Cochlear implants. Auditory prostheses and electric hearing. New York: Springer-Verlag; 2004.

6. Clark GM, Tong YC, Patrick JF, Seligman PM, Crosby PA, Kuzma JA i wsp. A multi-channel hearing prosthesis for profound-to-total hearing loss. J Med Eng Technol, 1984; 8(1): 3-8.

7. Battmer RD, Lehnhardt E. Clark implantable auditory prosthesis. Prerequisites and technic; report on the cochlear implant project of the ENT clinic of the Medical School in Hannover. Fortschr Med., 1985; 103(15): 397-400.
8. Wilson BS, Lawson DT, Müller JM, Tyler RS, Kiefer J. Cochlear implants: some likely next steps. Ann Rev Biomed Eng, 2003; 5: 207-49.

9. Wilson BS, Finley CC, Lawson DT, Wolford RD, Eddington DK, Rabinowitz WM. Better speech recognition with cochlear implants. Nature, 1991; 352: 236-8.

10. Zwolan TA, Kileny PR, Ashbaugh C, Telian SA. Patient performance with the Cochlear Corporation 20+2 implant: bipolar versus monopolar activation. Am J Otol, 1996; 17: 717-23.

11. Skarżyński H, Janczewski G, Niemczyk K, Geremek A. Cochlear implants: state of knowledge, prospects, indications for implantation. Otolaryngol Pol, 1993; 47(5): 444-51.

12. Skarżyński H, Janczewski G, Niemczyk K, Kochanek K, Geremek A, Klasek O. First cochlear implant in Poland. Otolaryngol Pol, 1993; 47(5): 427-34.

13. Michelson RP, Schindler RA. Multichannel cochlear implant preliminary results in man. Laryngoscope, 1981; 91(1): 38-42. 
14. Helms J, Müller J, Schön F, Moser L, Arnold W, Janssen T i wsp. Evaluation of performance with the COMBI40 cochlear implant in adults: a multicentric clinical study. ORL J Otorhinolaryngol Relat Spec, 1997; 59(1): 23-35.

15. Kiefer J, von Ilberg C, Reimer B, Knecht R, Gall V, Diller G i wsp. Results of cochlear implantation in patients with severe to profound hearing loss - implications for patients selection. Audiology, 1998; 37: 382-95.

16. Eisenberg L, House W. Initial experience with the cochlear implant in children. Annals of Otology, Rhinology and Laryngology Suppl, 1982; 91(2): 67-73.

17. Vermeire K, Anderson I, Flynn M, Ven de Heyning P. The influence of different speech processor and hearing aid settings on speech perception outcomes in electric acoustic stimulation patients. Ear Hear, 2008; 29: 76-86.

18. Anderson I, Weichbold V, D'Haese P. Three-year follow up of children with open-set speech recognition who use the MED-EL cochlear implant system. Cochlear Implants Int, 2004; 5(2): 45-57.

19. Anderson I, Weichbold V, D'Haese PS, Szuchnik J, Sainz Quevedo M, Martin J i wsp. Cochlear implantation in children under the age of two - what do the outcomes show us? Int J Pediatr Otorhinolaryngol, 2004; 68(4): 425-31.

20. Szuchnik J, Skarżyński H, Geremek A, Zawadzki R. Results of total deafness treatment in young pre- and postlingually deafened children. Scand Audiol Suppl, 2001; 52: 42-4.

21. Van de Heyning P, Kleine Punte A. Cochlear implants and hearing preservation. Karger; 2010.

22. Skarżyński H, Lorens A, Piotrowska A, Anderson I. Partial deafness cochlear implantation provides benefit to a new population of individuals with hearing loss. Acta Otolaryngol, 2006; 126(9): 934-40.

23. Arts HA, Garber A, Zwolan TA. Cochlear implants in young children. Otolaryngol Clin North Am, 2002; 35(4): 925-43.

24. Cheng A, Grant G, Niparko J. Meta-analysis of pediatric cochlear implant literature. Ann Otol Rhinol Laryngol Suppl, 1999; 177: 124-8.

25. Kileny P, Zwolan T, Ashbaugh C. The influence of age at implantation on performance with a cochlear implant in children. Otol Neurotol, 2001; 22(1): 42-6.

26. Colletti V, Carner M, Miorelli V, Guida M, Colletti L, Fiorino FG. Cochlear implantation at under 12 months: report on 10 patients. Laryngoscope, 2005; 115(3): 445-9.

27. Cosetti M, Roland JT. Cochlear implantation in the very young child: issues unique to the under-1 population. Trends Amplif, 2010; 14(1): 46-57.

28. Von Ilberg C, Kiefer J, Tillein H, Pfenningdorff T, Hartmann R, Sturzebecher E i wsp. Electric-Acoustic Stimulation of the auditory system. ORL J Otorhinolaryngol Relat Spec, 1999; 61: 334-40.

29. Skarżyński H, Lorens A, Piotrowska A, Anderson I. Partial deafness cochlear implantation in children. Int J Pediatr Otorhinolaryngol; 2007; 71(9): 1407-13.

30. Skarżyński H, Lorens A, Piotrowska A. A new method of partial deafness treatment. Med Sci Monit, 2003; 9(4): 26-30.

31. Skarżyński H, Lorens A, Piotrowska A, Skarżyński P. Hearing preservation in Partial Deafness Treatment (PDT). Medical Science Monitor, 2010; 16(11): 555-62.

32. Roland PS, Charles GW. Surgical aspects of cochlear implantation: mechanism of insertional trauma. Adv Otorhinolaryngol, 2006; 64: 11-30.

33. Roland PS, Wright CG, Isaacson B. Cochlear implant electrode insertion: The round window revisite. Laryngoscope, 2007; 117: 1397-402.
34. Fraysse B, Macías AR, Sterkers O, Burdo S, Ramsden R, Deguine $\mathrm{O}$ i wsp. Residual hearing conservation and electroacoustic stimulation with the nucleus 24 contour advance cochlear implant. Otol Neurotol, 2006; 27(5): 624-33.

35. Garcia-Ibanez L, Macias AR, Morera C, Rodriguez MM, Szyfter W, Skarzynski H i wsp. An evaluation of the preservation of residual hearing with the Nucleus Contour Advance electrode. Acta Otolaryngol, 2009; 129(6): 651-64.

36. Koch DB, Osberger MJ, Segel P, Kessler D. HiResolution and conventional sound processing in the HiResolution bionic ear: using appropriate outcome measures to assess speech recognition ability. Audiol Neurootol, 2004; 9(4): 214-23.

37. Adunka O, Kiefer J, Unkelbach MH, Lehnert T, Gstoettner W. Development and evaluation of an improved cochlear implant electrode design for electric acoustic stimulation. Laryngoscope, 2004; 114(7): 1237-41.

38. Helbig S, Van de Heyning P, Kiefer J, Baumann U, Kleine-Punte A, Brockmeier H i wsp. Combined electric acoustic stimulation with the PULSAR CI(100) implant system using the FLEX(EAS) electrode array. Acta Otolaryngol, 2011; 131(6): 585-95.

39. Gstoettner W, Helbig S, Settevendemie C, Baumann U, Wagenblast J, Arnoldner C. A new electrode for residual hearing preservation in cochlear implantation: first clinical results. Acta Otolaryngol, 2009; 129(4): 372-9.

40. Skarzynski H, Lorens A, Matusiak M, Porowski M, Skarzynski PH, James CJ. Partial Deafness Treatment with the Nucleus Straight Research Array Cochlear Implant. Audiol Neurotol, 2012; 17(2): 82-91.

41. Lorens A, Polak M, Piotrowska A, Skarżyński H. Outcomes of treatment of partial deafness with cochlear implantation: A DUET Study. Laryngoscope, 2008; 118(2): 288-94.

42. Won JH, Nie K, Drennan WR, Rubinstein JT. Maximizing the spectral and temporal benefits of two clinically used sound processing strategies for cochlear implants. Trends Amplif, 2012; 16(4): 201-10.

43. Hughes ML, Goulson AM. Electrically evoked compound action potential measures for virtual channels versus physical electrodes. Ear Hear, 201; 32(3): 323-30.

44. Buechner A, Brendel M, Saalfeld H, Litvak L, Frohne-Buechner C, Lenarz T. Results of a pilot study with a signal enhancement algorithm for HiRes 120 cochlear implant users. Otol Neurotol, 2010; 31(9): 1386-90.

45. Kam AC, Ng IH, Cheng MM, Wong TK, Tong MC. Evaluation of the ClearVoice Strategy in adults using HiResolution Fidelity 120 Sound Processing. Clin Exp Otorhinolaryngol, 2012; 5(1): 89-92.

46. Holden LK, Brenner C, Reeder RM, Firszt JB. Postlingual adult performance in noise with HiRes 120 and ClearVoice Low, Medium, and High. Cochlear Implants Int, 2013; 14(5): 276-86.

47. Skarzynski H, van de Heyning P, Agrawal S, Arauz SL, Atlas M, Baumgartner $\mathrm{W}$ i wsp. Towards a consensus on a hearing preservation classification system. Acta Otolaryngol Suppl., 2013; 564: 3-13.

48. Buechner A, Brendel M, Lesinski-Schiedat A, Wenzel G, Frohne-Buechner C, Jaeger B i wsp. Cochlear implantation in unilateral deaf subjects associated with ipsilateral tinnitus. Otol Neurotol, 2010; 31(9): 1381-5.

49. Kleinjung T, Steffens T, Strutz J, Langguth B. Curing tinnitus with a Cochlear Implant in a patient with unilateral sudden deafness: a case report. Cases J, 2009; 2(5): 7462.

50. Van de Heyning P, Vermeire K, Diebl M, Nopp P, Anderson I, de Ridder D. Incapacitating unilateral tinnitus in single-sided deafness treated by cochlear implantation. Ann Otol Rhinol Laryngol, 2008; 117(9): 645-52. 